\title{
Bactericidal Hydrogel Based on Sodium-Carboxymethylcellulose Contained Silver Nanoparticles: Obtaining and Properties
}

\author{
Yunusov Khaydar Ergashovich*, Sarymsakov Abdushkur Abdukhalilovich, \\ Rashidova Sayora Sharaphovna \\ Institute of Polymer Chemistry and Physics, Uzbekistan Academy of Sciences, Tashkent, Uzbekistan \\ Email: `haydar-yunusov@rambler.ru, polymer@academy.uz
}

How to cite this paper: Ergashovich, Y.K., Abdukhalilovich, S.A. and Sharaphovna, R.S. (2018) Bactericidal Hydrogel Based on Sodium-Carboxymethylcellulose Contained Silver Nanoparticles: Obtaining and Properties. Open Journal of Polymer Chemistry, 8, 57-69.

https://doi.org/10.4236/ojpchem.2018.84006

Received: July 29, 2018

Accepted: October 21, 2018

Published: October 24, 2018

Copyright $\odot 2018$ by authors and Scientific Research Publishing Inc. This work is licensed under the Creative Commons Attribution International License (CC BY 4.0).

http://creativecommons.org/licenses/by/4.0/

\begin{abstract}
Stable silver nanoparticles in a sodium-carboxymethylcellulose hydrogel with a substitution degree of 0.65 - 0.85 and polymerization degree of $200-600$ have been synthesized. Physical, chemical properties and antimicrobial activity of sodium-carboxymethylcellulose hydrogels contained silver nanoparticles were studied. The shape, number and size of silver nanoparticles (SNP) incorporated into the structure of hydrogels of sodium-carboxymethylcellulose were studied by using UV-VIS spectroscopy, transmission electron and atomic force microscopy. It was found that the silver nitrate concentration increase in sodium-carboxymethylcellulose solutions, as well as photoirradiation of the hydrogel lead to the changes of the silver nanoparticles size and shape. The studies have shown that the spherical silver nanoparticles of 5 - 35 $\mathrm{nm}$ in the structure of sodium-carboxymethylcellulose hydrogel possess high bactericidal activity. Our results have shown that changing of size and shape of silver nanoparticles contributes to appearance of their biological activity.
\end{abstract}

\section{Keywords}

Hydrogel, Silver Nanoparticles, Sodium-Carboxymethylcellulose, Substitution Degree, Polymerization Degree

\section{Introduction}

Metal-polymeric hydrogels based on polyelectrolytes contained silver nanoparticles show perspective ability to application them in the medical practice as bactericidal and bacteriostatic soft coatings for the treatment of burns and wounds [1]. 
Bactericidal metal-polymeric hydrogels for the treatment of burns and wounds must correspond to following requirements:

- should be prepared from non-toxic polymers which have prolong effect, good isolating and anti-microbial influence, sufficient air and vapor penetrability, and ability to prevent wound and burns from liquid evaporation; hydrogels should be transparent in order to control process of wound healing without removing a covering agent.

- hydrogels should hermetically cover the wounds or burns surface to protect the aggregation of exudate; hydrogels should be easily taken off the wound surface, washing painless with water and contain thixotropic agent preventing from dryness; hydrogels must be biodegradable, the time of complete resorption should be simultaneous with the time of wound healing; they should have a limited absorption capacity without changing the structure, and promote the formation of new epithelium [2] [3].

The goal of the present work is the formation of stable silver nanoparticles in the polymer based on sodium-carboxymethylcellulose (Na-CMC) hydrogels and study their structure, physicochemical properties and bactericidal activity.

\section{Experimental}

\subsection{Materials and Methods}

Purified Na-CMC with degree of substitution $(D S)=0.65-0.85$ and degree of polymerization $(\mathrm{DP})=200-600$ obtained from cotton cellulose (CC) was used as a polymeric matrix. An aqueous solution of silver nitrate (GOST 1277-75 Reagents $\mathrm{AgNO}_{3}$, Specifications) was used for the formation of silver nanoparticles in the structure of $\mathrm{Na}-\mathrm{CMC}$ hydrogel.

\subsection{Synthesis of Silver Nanoparticles}

For the obtaining Na-CMC hydrogels 2\% - 4\% aqueous solutions of purified Na-CMC samples with various DS and DP were selected after removal of gel fraction on a laboratory centrifuge MLW-T23 (Hungary) at $6000 \mathrm{rpm}$ for 20 minutes.

An aqueous solution of $\mathrm{AgNO}_{3}$ with calculated concentrations of $0.1-0.01 \mathrm{M}$ was added under stirring to $\mathrm{Na}-\mathrm{CMC}$ solutions free of gel fraction, and stirring was continued until a homogeneous $\mathrm{Ag}^{+} \mathrm{CMC}^{-}$hydrogel formation. Photochemical restoration of silver ions to nanoparticles in the structure of $\mathrm{Ag}^{+} \mathrm{CMC}^{-}$was performed at $25^{\circ} \mathrm{C}$ using a high pressure mercury lamp DRSh 250-3, $\lambda=365 \mathrm{~nm}$ (Russia).

\subsection{Physicochemical Methods of Investigation}

For the obtaining of Na-CMC hydrogel contained dispersed silver nanoparticles an ultrasonic disperser USDN-1, U-4.2, $44 \mathrm{kHz}$ (Russia) was used. Viscosity of $\mathrm{Na}-\mathrm{CMC}$ and $\mathrm{Ag}^{+} \mathrm{CMC}^{-}$solutions was determined on a glass capillary viscometer VPJ-2 with capillary diameter $0.56 \mathrm{~mm}$. 
The optical absorption spectra of hydrogels were recorded on a Specord M210 UV-Vis spectrophotometer (Germany) at the wavelength range from 200 to 900 $\mathrm{nm}$. The length of optical channels was $2 \mathrm{~mm}$. The morphology of the nanometal-polymer surface layers was studied using a transmission electron microscope TEM-100 (Ukraine) and an atomic-force microscope AFM-5500 (Austria) in films obtained from hydrogels of $\mathrm{Na}-\mathrm{CMC}, \mathrm{Ag}^{+} \mathrm{CMC}^{-}$and $\mathrm{Ag}^{0} \mathrm{CMC}$. The distribution of metal particles in polymer matrix by size, and the variation coefficient was determined by the calculation of the corresponding photomicrographs in MathCad program.

\subsection{Determination of Bactericidal Activity}

For the testing of bacterial activity of hydrogels the pathogen microorganisms Staphylococcus epidermidis and Candida albicans were used. The following samples were added to test-tubes containing Thioglycollic medium (for Staphylococcus epidermidis) and Saburo (for Candida albicans): 1) Control $\mathrm{Na}-\mathrm{CMC}$ hydrogel; 2) Na-CMC hydrogel contained $\mathrm{Ag}^{+}, \mathrm{C}_{\mathrm{Ag}}^{+}=0.025$ wt.\%; 3) Na-CMC hydrogel contained $\mathrm{Ag}^{0}, \mathrm{C}_{\mathrm{Ag}}^{0}=0.025 \mathrm{wt} . \%$; 4) Na-CMC hydrogel contained $\mathrm{Ag}^{0}, \mathrm{C}_{\mathrm{Ag}}^{0}=0.25$ wt.\%; 5) Na-CMC hydrogel contained $\mathrm{Ag}^{0}, \mathrm{C}_{\mathrm{Ag}}^{0}$ $=2.5 \mathrm{wt} . \%$.

$10 \% \mathrm{NaCl}$ solution in the same medium was used as a control. Within six hours, the final concentration of 150 cells/ml test culture was added in each test-tube. Samples were incubated at $34^{\circ} \mathrm{C}$ during 48 hours (for Staphylococcus epidermidis) and $72 \mathrm{~h}$ (for Candida albicans).

\section{Results and Discussion}

Solubility and purity degree are the most important physicochemical characteristics of Na-CMC that determine possibility of their application in some products. We investigated the composition of water-soluble and insoluble fractions of purified Na-CMC samples with different DS and DP.

As seen from Table 1, with increasing DS, a part of soluble Na-CMC fraction in water is increased, and content of insoluble gel fraction is decreased. With increasing DS, part of gel fraction of Na-CMC in water decreases.

Probably, it occurs due to the decreasing of hydrogen bonds intensity between the macromolecules and an increasing of DS in Na-CMC. Moreover, the composition and properties of $\mathrm{Na}-\mathrm{CMC}$ gel fraction depend on the type of cellulose raw material and methods of $\mathrm{Na}-\mathrm{CMC}$ obtaining.

It was found that the content of gel fraction in Na-CMC samples of cotton pulp in all DP and DS intervals is more than those of Na-CMC sample 4 (Table 1). This could be explained by high DS of Na-CMC. The above-described investigation provided a polymeric matrix for the Na-CMC hydrogel contained ions and silver nanoparticles.

Further studies were aimed at the formation and stabilization of silver ions and nanoparticles in Na-CMC polymer base and study their properties. Aqueous 
Table 1. Effects of DS and DP of Na-CMC samples on quantity and composition of water-soluble and insoluble fractions.

\begin{tabular}{ccccccccc}
\hline \multicolumn{7}{c}{$\begin{array}{c}\text { Indexes of purified } \\
\text { Na-CMC samples }\end{array}$} & \multicolumn{7}{c}{ Indexes of Na-CMC samples after their centrifugation } \\
\hline $\begin{array}{c}\text { Samples of } \\
\text { Na-CMC } \\
\text { from CC }\end{array}$ & DS & DP & $\begin{array}{c}\text { Soluble } \\
\text { fractions, } \%\end{array}$ & DS & DP & $\begin{array}{c}\text { Gel } \\
\text { fractions, \% }\end{array}$ & DS & DP \\
\hline 1 & 0.62 & 210 & 71 & 0.65 & 200 & 29 & 0.11 & 230 \\
2 & 0.67 & 320 & 75 & 0.69 & 300 & 25 & 0.12 & 380 \\
3 & 0.82 & 520 & 98 & 0.85 & 510 & 3 & 0.15 & 600 \\
4 & 0.85 & 610 & 99 & 0.88 & 600 & 1 & 0.17 & 700 \\
\hline
\end{tabular}

solutions of Na-CMC exhibited the properties of polyelectrolyte. Derivatives of Na-CMC with alkali metal ions such as $\mathrm{Na}^{+}, \mathrm{K}^{+}, \mathrm{NH}_{4}^{+}$are quickly soluble in water [4].

Na-CMC compounds with polyvalent metals such as calcium, magnesium, copper, lead, and zirconium are insoluble in water due to the intermolecular cross-linking, and they form stable hydrogels. Sediment gel forms by aluminum ions addition to Na-CMC solution [5]. Table 2 shows the characteristics of $\mathrm{Na}-\mathrm{CMC}$ samples with different DS and DP contained different amounts of silver ions.

We have studied the conditions and the replacement of sodium ions by silver ions in $\mathrm{Na}-\mathrm{CMC}$ solutions. It was determined that when $\mathrm{Na}^{+}$-ions in $\mathrm{Na}-\mathrm{CMC}$ with DS $0.65 ; 0.69 ; 0.85 ; 0.88$ replaced by $0.35 ; 0.4 ; 0.5$ and $0.6 \mathrm{~mol} \%$ ions of $\mathrm{Ag}^{+}$, a stable $\mathrm{Ag}^{+} \mathrm{CMC}^{-}$hydrogel bad soluble in water is formed, in opposite to alkali metal salts of Na-CMC. Apparently, carboxyl groups of Na-CMC are able form a complex ion with ions of silver [6].

The limits of $\mathrm{Ag}^{+} \mathrm{CMC}^{-}$hydrogels formation defined as the content of silver ions and the molecular parameters of $\mathrm{Na}-\mathrm{CMC}$ are presented in the Table 2. With increasing of Na-CMC DS, the concentration of silver ions necessary for the formation of bad soluble in water $\mathrm{Ag}^{+} \mathrm{CMC}^{-}$hydrogel is increased.

Numerous studies have shown that silver nanoparticle contained materials possess a good antimicrobial and wound healing properties [7]. Therefore, we have studied the conditions of obtaining $\mathrm{Ag}^{+} \mathrm{CMC}^{-}$hydrogels contained stabilized silver nanoparticles by using photochemical methods [8]. Comparison of different methods of silver ions reduction to nanometallic state has shown that the photochemical reduction is the most effective to control the size of nanoparticles and obtain products pure of the reducing agent transformation products [9].

Stable nanoparticles synthesized by photochemical method have a narrow distribution in particle sizes and high stability in an aqueous medium (chemical reduction, high-frequency electric discharge, ultrasonic dispersing, and the condensation of metal vapors) being used as matrix ionic polymer solution that simultaneously function as nanoparticle stabilizing agent, in compare to colloidal 
Table 2. Physicochemical characteristics of $\mathrm{Na}-\mathrm{CMC}$ containing silver ions.

\begin{tabular}{|c|c|c|c|c|c|}
\hline \multirow{2}{*}{$\begin{array}{l}\text { Samples of } \\
\text { Na-CMC }\end{array}$} & \multicolumn{2}{|c|}{$\begin{array}{c}\text { Characteristic of } \\
\mathrm{Na}-\mathrm{CMC}\end{array}$} & \multirow{2}{*}{$\begin{array}{l}\text { Content of silver } \\
\text { ions, mol\% }\end{array}$} & \multirow{2}{*}{$\begin{array}{l}\text { Solubility in } \\
\text { water, \% }\end{array}$} & \multirow{2}{*}{$\begin{array}{c}\text { Relative viscosity } \\
{\left[\eta_{\text {rel }}\right]}\end{array}$} \\
\hline & $\mathrm{DP}$ & DS & & & \\
\hline \multirow{5}{*}{1} & \multirow{5}{*}{0.65} & \multirow{5}{*}{200} & - & 71.0 & 1.223 \\
\hline & & & 0.05 & 63.6 & 1.721 \\
\hline & & & 0.10 & 44.2 & 2.342 \\
\hline & & & 0.25 & 29.7 & 2.983 \\
\hline & & & 0.35 & 18.1 & Hydrogel \\
\hline \multirow{5}{*}{2} & \multirow{5}{*}{0.69} & \multirow{5}{*}{300} & - & 75.0 & 1.470 \\
\hline & & & 0.05 & 69.8 & 1.841 \\
\hline & & & 0.10 & 58.5 & 2.985 \\
\hline & & & 0.30 & 34.7 & 3.543 \\
\hline & & & 0.40 & 26.2 & Hydrogel \\
\hline \multirow{5}{*}{3} & \multirow{5}{*}{0.85} & \multirow{5}{*}{510} & - & 98.0 & 2.128 \\
\hline & & & 0.10 & 89.3 & 2.651 \\
\hline & & & 0.20 & 56.0 & 3.426 \\
\hline & & & 0.40 & 30.8 & 4.576 \\
\hline & & & 0.50 & 14.9 & Hydrogel \\
\hline \multirow{5}{*}{4} & \multirow{5}{*}{0.88} & \multirow{5}{*}{600} & - & 99.0 & 1.894 \\
\hline & & & 0.15 & 92.0 & 1.912 \\
\hline & & & 0.20 & 64.7 & 2.732 \\
\hline & & & 0.45 & 27.5 & 3.871 \\
\hline & & & 0.60 & 19.0 & Hydrogel \\
\hline
\end{tabular}

systems obtained by traditional method. Photochemical method makes possible the management of process in-time and in-site, as distinct from the chemical methods applying thermodynamically and kinetically unstable systems [10].

It is known that the formation of colloidal silver particles in prolonged photon irradiation above the band-gap is the basis of the photographic process in silver halides. This electron-stimulated process of colloidal particles formation has been explained by the Mott-Gurney theory [11] [12]. During photochemical reduction, the optically generated electron migrates and catches with the electron catcher at the bedding interface and near the surface. The negative charge attracts one of interstitial $\mathrm{Ag}^{+}$ions presented in thermodynamic equilibrium which move to the trapped electron. This is the first step in the sequence of the electrons and interstitial atoms trapping and formation of silver clusters and nanoparticles as a basis of latent image.

Analyzing spectroscopic data of based on silver nanoparticles and Na-CMC nanocomposites, it may suppose that the negative ion in carboxymethyl group is "a trap" for the positively charged silver ion [12]. 
Then, the reaction sequence on the mechanism of the Mott-Gurney will be as follow:

\begin{tabular}{cccc}
\hline $\mathrm{R}-\mathrm{COO}^{-}+\left(\mathrm{Ag}^{+}\right)_{\mathrm{n}}$ & $\mathrm{h} v \longrightarrow$ & $\mathrm{R}-\mathrm{COO}^{\circ}: \mathrm{Ag}^{0}$ & (1) \\
$\mathrm{R}-\mathrm{COO}: \mathrm{Ag}^{0}+\mathrm{e}$ & $\mathrm{R}-\mathrm{COO}^{-}: \mathrm{Ag}^{0}$ & (2) \\
$\mathrm{R}-\mathrm{COO}^{-}: \mathrm{Ag}^{0}+\mathrm{Ag}^{+}$ & $\mathrm{R}-\mathrm{COO}^{\circ}: \mathrm{Ag}_{2}^{0}$ & (3) \\
$\mathrm{R}-\mathrm{COO}^{-}: \mathrm{Ag}_{2}^{0}$ & $\mathrm{R}-\mathrm{COO}^{-}:\left(\mathrm{Ag}^{0}\right)_{\mathrm{n}}$ & (n) \\
\hline
\end{tabular}

Thus, the photostimulated formation of silver nanoparticles in the $\mathrm{Ag}^{+} \mathrm{CMC}^{-}$ hydrogel can be considered as electron-stimulated nuclear process that may be based on Mott-Gurney theory [11] as the photography process.

To confirm this assumption, spectra of $\mathrm{Na}-\mathrm{CMC}, \mathrm{Ag}^{+} \mathrm{CMC}^{-}$, and $\mathrm{Ag}^{0} \mathrm{CMC}$ were taken. After UV-irradiation, Na-CMC solutions containing silver ions formed enough stable colloidal systems of nanosilver of pale-yellow color with maximum at $\lambda_{\max }=416 \mathrm{~nm}$ attributed to silver nanoparticles of $5-25 \mathrm{~nm}$ [12] (Figure 1, curve-3).

No changes were observed in the spectra of initial $\mathrm{Na}-\mathrm{CMC}$ solutions (Figure 1, curve-1) and no unreduced silver ions in $\mathrm{Ag}^{+} \mathrm{CMC}^{-}$(Figure 1, curve-2) at 250 $-900 \mathrm{~nm}$.

With increasing the time of photolysis the color of solutions is changed from pale yellow to brown. According to the literature [12], such changes are probably depended on the increased quantity and size of silver nanoparticles.

To confirm this assumption, absorption spectra were taken at the different periods of irradiation of $\mathrm{Ag}^{+} \mathrm{CMC}^{-}$systems at Na-CMC concentration of 0.008 $\mathrm{mol}(2 \%)$ and silver nitrate of $3 \times 10^{-5} \mathrm{~mol}$. Figure 2 shows the UV-spectrum of $\mathrm{Na}-\mathrm{CMC}$ hydrogel contained silver nanoparticles which obtained at different photo irradiation periods.

As can be seen in Figure 2., the shoulder at the region $\lambda_{\max }=270 \mathrm{~nm}$ had been observed in the spectrum (Figure 2, curve-2) in 5 minutes of photo irradiation which could be attributed to stable polyanion charged silver clusters, approximately $\mathrm{Ag}_{8}^{2+}$ [12] [13].

In 15 and 20 minutes of photolysis, increasing of the absorption band intensity at $\lambda_{\max }=270 \mathrm{~nm}$ (Figure 2, curves-2,3) had been observed at the spectrum which depends on formation of large stabilized clusters of silver with sizes $2-8$ $\mathrm{nm}$, and $\lambda_{\max }=420 \mathrm{~nm}$ (Figure 2, curve-4) attributed to the larger silver nanoparticles with sizes of $5-35 \mathrm{~nm}$ [13].

Further irradiation till 60 minutes led to the appearance of absorption bands with maxima at regions $\lambda_{\max }=290 \mathrm{~nm}$ and $\lambda_{\max }=420 \mathrm{~nm}$ (Figure 2, curve-5) is due to increasing of the number of larger clusters and silver nanoparticles of 5 $35 \mathrm{~nm}[13]$.

In addition, a weak maximum in the near-IR region of the spectrum in $\lambda_{\max }=$ $850 \mathrm{~nm}$ (Figure 2, curve-5) is observed owing to exclusively rod-shaped silver nanoparticles [13]. 




Figure 1. UV-VIS absorption spectra of the samples: 1) $\mathrm{Na}-\mathrm{CMC}, 2) \mathrm{Ag}^{+} \mathrm{CMC}^{-}, 3$ ) $\mathrm{Ag}^{0} \mathrm{CMC}$. Time of UV-irradiation for samples was $25 \mathrm{~min}$; [Na-CMC] $=0.008 \mathrm{~mol}(2 \%)$; $\left[\mathrm{AgNO}_{3}\right]=3 \times 10^{-5} \mathrm{~mol}(0.25 \mathrm{wt} . \%)$.

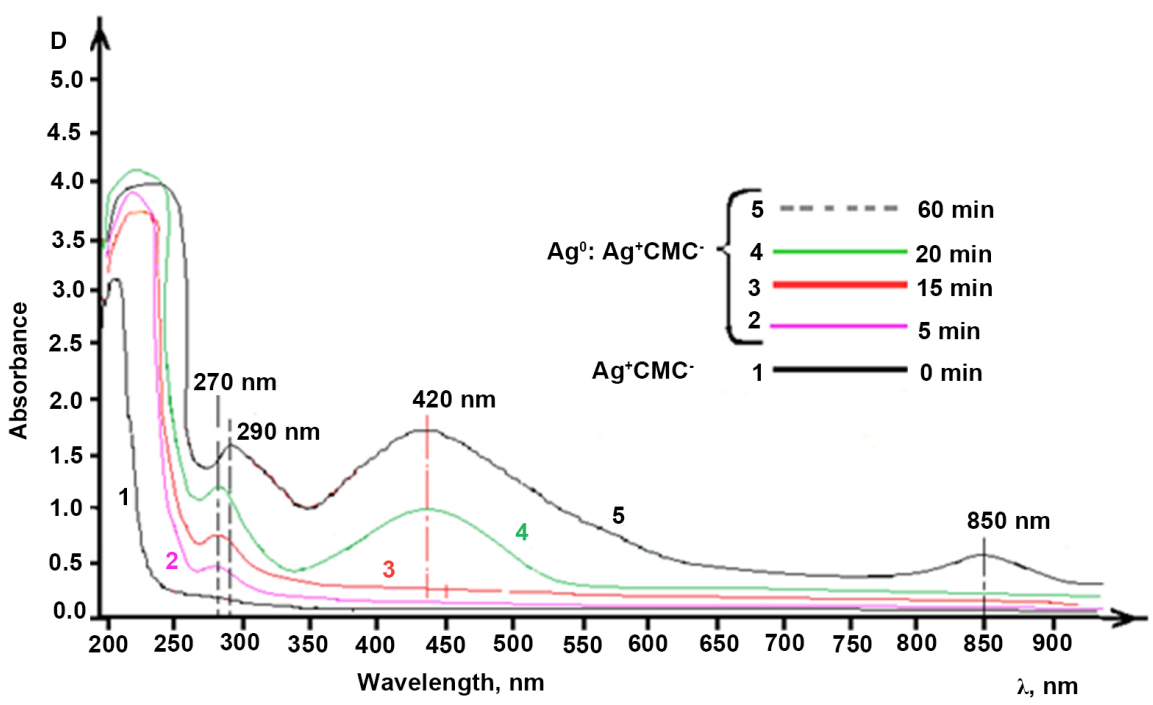

Figure 2. UV-VIS absorption spectra of photochemical reduction of silver ions in $\mathrm{Ag}^{+} \mathrm{CMC}^{-}$samples. Concentration of $[\mathrm{Na}-\mathrm{CMC}]=0.008 \mathrm{~mol}(2 \%)$; and $\left[\mathrm{AgNO}_{3}\right]=3 \times$ $10^{-5} \mathrm{~mol}(0.25$ wt.\%). Period of UV-irradiation 0 (1), 5 (2), 15 (3), 20 (4), and 60 (5).

For the purpose of shapes and sizes of silver nanoparticles determination in $\mathrm{Na}-\mathrm{CMC}$ structure the obtained samples were investigate on a TEM microscope. Impact time of UV-irradiation to changing the sizes and shapes of silver nanoparticles are presented in Figure 3.

It was established that at UV-irradiation of samples in 15 minutes spherical silver nanoparticles with the sizes from $2-20 \mathrm{~nm}$ till $5-35 \mathrm{~nm}$ (Figure 3(a), Figure 3(b)) are formed. At further UV-irradiation till 60 minutes the spherical nanoparticles turn into bigger with sizes $50-100 \mathrm{~nm}$ (Figure 3(c)) due to a simultaneous restoration of silver ions bound to carboxyl anions in Na-CMC structure and free silver ions. These processes proceed with different speed and lead to increase of polydispersion and nanoparticles shape changing. 


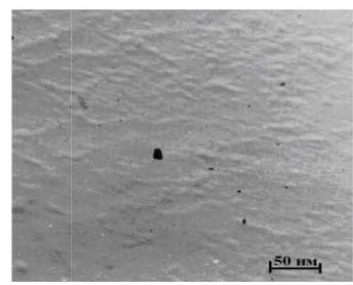

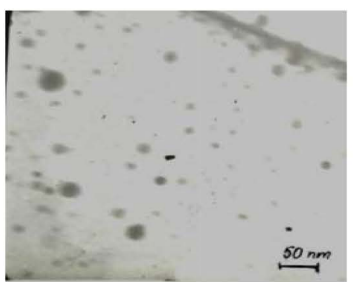

(a) $2-20 \mathrm{~nm}$

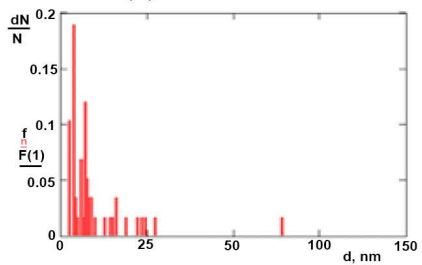

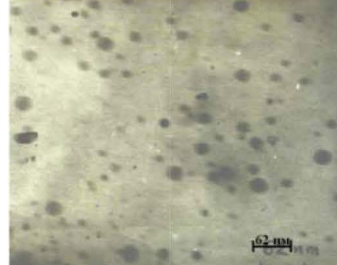

(b) $5-35 \mathrm{~nm}$

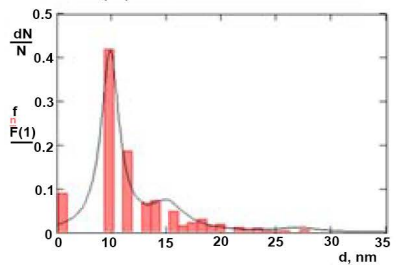

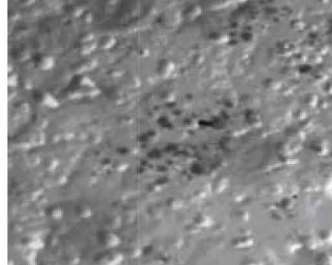

(c) $1=50-100 \mathrm{~nm}$

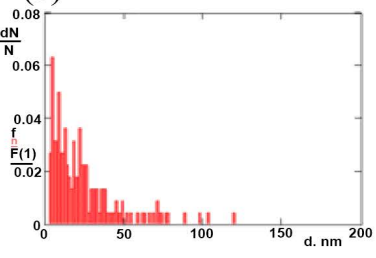

Figure 3. AFM microphotograph of Na-CMC hydrogel contained SNP (a), (b), (c) and their histograms. Concentration of $[\mathrm{Na}-\mathrm{CMC}]=8 \times 10^{-3} \mathrm{~mol}(2 \%) ;\left[\mathrm{AgNO}_{3}\right]=3 \times 10^{-5} \mathrm{~mol}(0.25 \mathrm{wt} . \%)$. Time of UV-irradiations $20 \mathrm{~min}$. (a); $30 \mathrm{~min}$. (b); $60 \mathrm{~min}$. (c).

In the next step we studied impact of silver ions concentration to changing size and form of silver nanoparticles in Na-CMC hydrogel. Transmission electron microscopy investigation of $\mathrm{Ag}^{+} \mathrm{CMC}^{-}$metal complexes of contained silver nanoparticles was carried out (Figure 4).

TEM images are shown, that at low concentrations $(0.025$ wt.\% and 0.25 wt.\%) $\mathrm{AgNO}_{3}$ formed spherical silver nanoparticles with sizes of $0.65-8 \mathrm{~nm}$ (Figure 4(b)) and 2 - $30 \mathrm{~nm}$ (Figure 4(c)). With increasing of $\mathrm{AgNO}_{3}$ concentration in Na-CMC hydrogel up to $2.5 \mathrm{wt} . \%$, nanoparticles become rod-shape with $\mathrm{l}=40-120 \mathrm{~nm}$ and $\mathrm{d}=5-60 \mathrm{~nm}$ (Figure $4(\mathrm{~d})$ ).

The mechanism of rod-like shaped silver nanoparticle formation in these conditions is still unclear [14]. Thus, the size and shape of silver nanoparticles formed in $\mathrm{Ag}^{+} \mathrm{CMC}^{-}$hydrogels by photochemical reduction of silver ions depend on DS, concentration of Na-CMC solution, concentration of $\mathrm{Ag}^{+}$, and time of photochemical irradiation. In the presence of $\mathrm{Na}-\mathrm{CMC}$ the macroanions effectively bind $\mathrm{Ag}^{+}$-ions, and the UV reduction led to the successive formation of clusters and nanosilver depending on the concentration of silver ions.

Decrease of the carboxymethyl anions relative content caused by lowering of the reaction medium $\mathrm{pH}$ calls a dramatic decrease in the efficiency of silver ions binding after their UV-irradiation because of their aggregation with the formation of silver nanorods. It could be explained by the increasing of silver ions concentration in CMC structure with simultaneous restoration of silver ions bound to carboxylate anion of Na-CMC (nanoreactor) [10] and free silver ions. These processes carry out with different speeds and lead to polydispersity of formed nanoparticles.

Increase of particle sizes, their aggregation and change of spherical shape suggest that the macromolecular envelope forming in decrease of concentration of $\mathrm{Ag}^{+} \mathrm{CMC}^{-}$complexes, essentially being centers of photoreduction and subsequent growth of nanoparticles, becomes less solid. At that, the growth, coagulation, and possibly, coalescence of particles continue. 


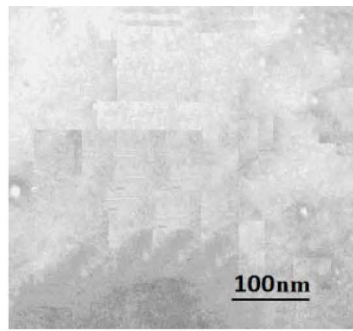

(a)

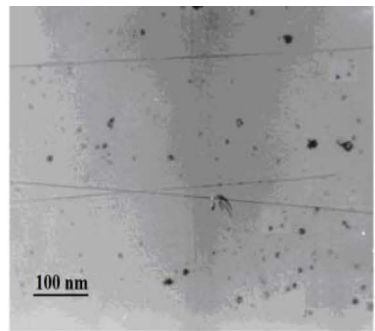

(b) $0.65-8 \mathrm{~nm}$

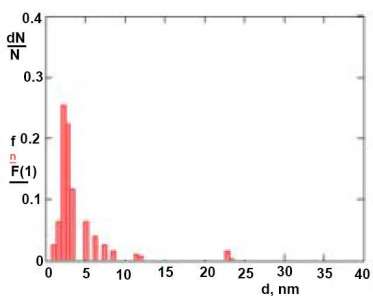

(b)

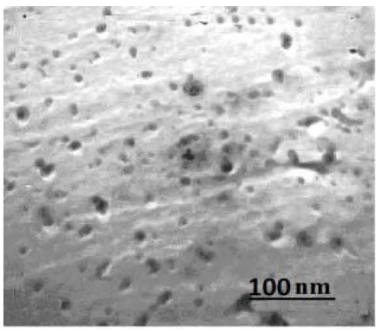

(c) 2 - $30 \mathrm{~nm}$

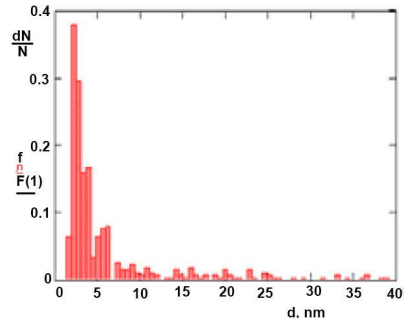

(c)

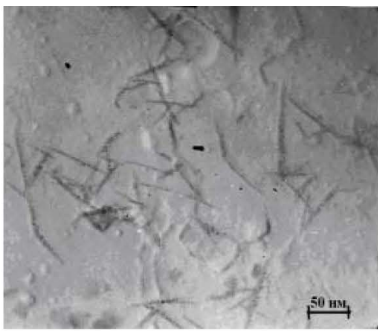

(d) $1=40-120 \mathrm{~nm}$, $\mathrm{d}=5-60 \mathrm{~nm}$



(d)

Figure 4. TEM micrographs of Na-CMC hydrogel contained silver nanoparticles. (a) pure Na-CMC soluteon; (b) Na-CMC: $\mathrm{AgNO}_{3}\left(0.08: 3 \times 10^{-6} \mathrm{~mol}\right) 0.025$ wt.\% $\mathrm{AgNO}_{3}$; (c) Na-CMC:AgNO${ }_{3}\left(0.08: 3 \times 10^{-5} \mathrm{~mol}\right) 0.25$ wt.\% AgNO ${ }_{3}$, with spherical structure of silver nanoparticles; (d) Na-CMC: $\mathrm{AgNO}_{3}\left(0.08: 3 \times 10^{-4} \mathrm{~mol}\right) 2.5 \mathrm{wt} . \% \mathrm{AgNO}_{3}$ rod-shape structure of silver nanoparticles.

The homogeneity of nanoparticle sizes is reach due to formation of the $\mathrm{Na}-\mathrm{CMC}$ macromolecule charged envelopes that cover silver nanoparticles and prevent their aggregation. Increasing of $\mathrm{Na}-\mathrm{CMC}$ local concentration, by one hand, provides an electrostatic and steric stabilization of silver nanoparticles, and, by other hand, creates conditions in which the complete removal of radicals interaction in UV-photolysis of $\mathrm{Ag}^{+} \mathrm{CMC}^{-}$is impossible. To evaluate stability of the silver nanoparticles formed in Na-CMC hydrogels, the UV spectra of Na-CMC hydrogels contained silver nanoparticles (Figure 5(a), Figure 5(b)) kept for the different time periods were taken.

As it can be seen from Figure 5(b), the shape and content of silver nanoparticles in Na-CMC hydrogels during prolonged keeping under $25^{\circ} \mathrm{C}$ did not change. Basing on the experimental results, we can conclude that, depending on the molecular weight, degree of substitution, the ratio of $\mathrm{Na}-\mathrm{CMC}$ and $\mathrm{AgNO}_{3}$, and the reaction conditions, the size and shape of silver nanoparticles formed in $\mathrm{Na}-\mathrm{CMC}$ hydrogels by the photochemical reduction can be controlled.

The following conditions of homogeneous silver nanoparticles formation were chosen:

Time of UV-irradiation 30 minutes; content of $\mathrm{Na}-\mathrm{CMC}$ in solution 0.008 mol; content of $\mathrm{AgNO}_{3}$ in solution $3 \times 10^{-5} \mathrm{~mol}$. Spherical silver nanoparticles of $5-35 \mathrm{~nm}$ formed in hydrogel at the selected conditions. Stabled shape and size of silver nanoparticles in the Na-CMC hydrogel structure in long keeping confirms the important role of the chosen polymer matrix stabilization.

The biological activity of silver nanoparticles formed in Na-CMC hydrogels were investigated on Staphylococcus epidermidis and Candida albicans strains. 


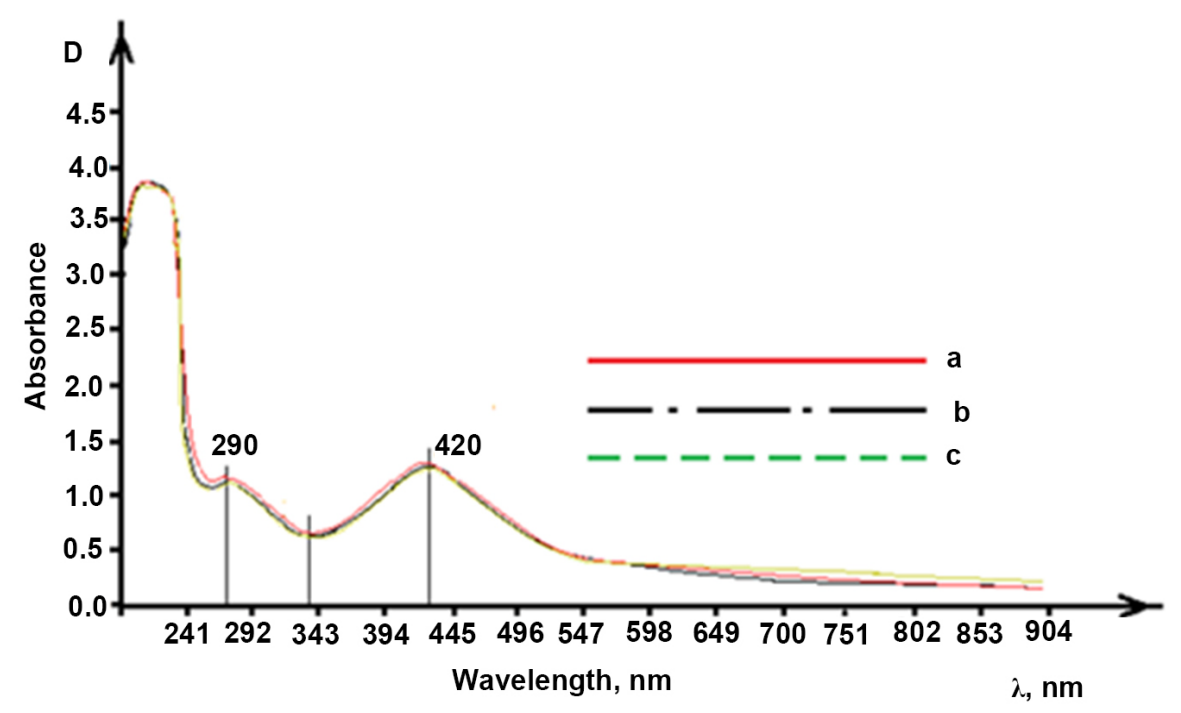

Figure 5. UV-absorption spectra of Na-CMC hydrogels contained silver nanoparticles at the different time periods. Time of UV irradiation is $30 \mathrm{~min}$. Concentration of $\mathrm{AgNO}_{3}$ is 0.25 wt.\%. (a) The absorption spectra taken after hydrogels obtaining; (b) The absorption spectra of hydrogels after one month. (c) The absorption spectra of hydrogels after six months.

$2 \% \mathrm{Na}-\mathrm{CMC}$ hydrogel was selected as a control, an aqueous solution of silver nitrate, $2 \% \mathrm{Ag}^{+} \mathrm{CMC}^{-}$hydrogel, and $\mathrm{Na}-\mathrm{CMC}$ hydrogel contained silver nanoparticles were taken as test objects. Microbiological investigations of the above samples were carried out using method [15]. Results of investigation presented in Table 3.

As shown in Table 3, the control sample 2\% Na-CMC hydrogel has no antimicrobial activity of the polymeric matrix in both microorganism strains. An aqueous solution of $\mathrm{AgNO}_{3}$ exhibited bacteriostatic activity against Staphylococcus epidermidis, but no activity against Candida albicans.

Silver ions contained Na-CMC hydrogel exhibited bacteriostatic activity against Staphylococcus epidermidis at 30\% higher than the water solution of silver nitrate at the similar concentration. It doesn't show antimicrobial activity against Candida albicans.

The relatively high activity of the silver ions in the structure of $\mathrm{Na}-\mathrm{CMC}$ against free silver nitrate ions because silver nitrate ions of their high movability in aqueous solutions and quickly connects with functional groups on the surface strains as Staphylococcus epidermidis and fungus Candida albicans. The silver ions being in the structure of $\mathrm{Na}-\mathrm{CMC}$ hydrogel have limited mobility and keep the biological activity for a long time.

In the examination $\mathrm{Na}-\mathrm{CMC}$ hydrogel, contained silver nanoparticles was found that they are active anti strains of Staphylococcus epidermidis for three times higher than an aqueous solution silver nitrate, and exhibit a high bactericidal activity against fungi Candida albicans, this evidence by the absence of fungal growth medium. 
The relatively high antimicrobial activity of silver nanoparticles in compare with silver ions may be caused by:

- Inability of silver nanoparticles make chemical bonds with the functional groups on the surface of Staphylococcus epidermidis and Candida albicans cells, and, probably, by their ability to penetrate into the nucleus of cells and inhibit their growth and activity [16];

- Lowering of the silver nanoparticle sizes lead to increasing of the total surface area and acceleration of their contact and penetration into the both strains cell nucleus ability;

- Increasing of nanoparticle sizes and changing of their shape from spherical to rod-shaped, on the one hand, bring to fast decrease of total surface area, and, on the other hand, to limited ability of entering into the cell nucleus of Staphylococcus epidermidis and Candida albicans strains.

Comparative antimicrobial activity of silver nanoparticles with different sizes and shapes are presented in Table 4. Na-CMC hydrogels containing silver nanoparticles with spherical structures and sizes 5 - $35 \mathrm{~nm}$ showed a highest activity against Staphylococcus epidermidis and Candida albicans due to high values of their surface area and ability to penetrate into the cell nucleus [16] [17]. $\mathrm{Na}-\mathrm{CMC}$ hydrogel contained rod-shape silver nanoparticles with $\mathrm{l}=50-140 \mathrm{~nm}$ and $\mathrm{d}=15-40 \mathrm{~nm}$ was less active than hydrogels contained silver nanoparticles with spherical structure, but they are more active in compare to Na-CMC hydrogel contained silver ions.

Table 3. Comparative results of investigation of the bactericidal activity of Na-CMC hydrogels contained silver ions and silver nanoparticles.

\begin{tabular}{cccc}
\hline & & \multicolumn{2}{c}{ Strains } \\
\cline { 3 - 4 } No. & Samples & Staphylococcus epidermidis & Candida albicans \\
\hline 1 & Control 2 \% of Na-CMC hydrogel & $1000 \mathrm{CFU} / \mathrm{ml}$ & $1000 \mathrm{CFU} / \mathrm{ml}$ \\
2 & $0.1 \mathrm{M}$ water solution of $\mathrm{AgNO}_{3}$ & $6 \mathrm{CFU} / \mathrm{ml}$ & Confluent growth \\
3 & $\mathrm{Ag}^{+} \mathrm{CMC}^{-}$hydrogel & $4 \mathrm{CFU} / \mathrm{ml}$ & Confluent growth \\
4 & $\mathrm{Ag}^{0} \mathrm{CMC}$ hydrogel & $2 \mathrm{CFU} / \mathrm{ml}$ & Absent \\
\hline
\end{tabular}

Note. Colony of forming unit $\mathrm{CFU} / \mathrm{ml}-\mathrm{a}$ unit of measurement is the number of colony forming units per milliliter of fluid.

Table 4. Comparative results of the antimicrobial activity of Na-CMC hydrogel contained silver nanoparticles of different shapes and sizes.

\begin{tabular}{|c|c|c|c|c|}
\hline \multirow[b]{2}{*}{ No. } & \multirow{2}{*}{$\begin{array}{c}\text { Samples of } \\
\mathrm{Ag}^{0} \mathrm{CMC} \text { hydrogel } \\
\mathrm{C} \text {-wt.\%, } \mathrm{AgNO}_{3}\end{array}$} & \multirow{2}{*}{$\begin{array}{l}\text { Shape and size of silver } \\
\text { nanoparticles }\end{array}$} & \multicolumn{2}{|c|}{ Strains } \\
\hline & & & $\begin{array}{c}\text { Staphylococcus } \\
\text { epidermidis }\end{array}$ & Candida albicans \\
\hline 1 & Control & & $5 \times 10^{12} \mathrm{CFU} / \mathrm{ml}$ & $1 \times 10^{7} \mathrm{CFU} / \mathrm{ml}$ \\
\hline 2 & 0.025 & $2-20 \mathrm{~nm}$ & $1 \times 10^{10} \mathrm{CFU} / \mathrm{ml}$ & $1 \times 10^{5} \mathrm{CFU} / \mathrm{ml}$ \\
\hline 3 & 0.25 & (spherical) $5-35 \mathrm{~nm}$ & Absent & Absent \\
\hline 4 & 2.5 & $\begin{array}{c}(\text { rod-like }) \\
1=50-140 \mathrm{~nm}, \mathrm{~d}=15-40 \mathrm{~nm}\end{array}$ & $2 \times 10^{8} \mathrm{CFU} / \mathrm{ml}$ & $1 \times 10^{4} \mathrm{CFU} / \mathrm{ml}$ \\
\hline
\end{tabular}


In addition, Na-CMC hydrogel containing 2 - $20 \mathrm{~nm}$ silver nanoparticles was proved to be less active than other hydrogels. This result may be explained by the fact that the total content of silver nanoparticles in such Na-CMC hydrogel turned out to be almost an order of magnitude less than in the samples of hydrogel containing 5 - $35 \mathrm{~nm}$ (spherical) and rod-shaped nanoparticles of silver.

\section{Conclusions}

Optimal conditions of silver nanoparticles with different shapes and sizes formation in the structure of Na-CMChydrogels of different DS and DP were determined by the photoirradiation of hydrogels.

It was established that the replaced silver ions in Na-CMC macromolecules mainly subject to restoration and play the role of $<$ nanoreactors $>$ in which the carboxylic groups of a negative ion, according to the theory of Mott-Gurney, are the $<$ trap $>$ for positively charged ions of silver and promote the photostimulated formation of silver nanoparticles. UV-spectroscopic method for control of the form and sizes of silver nanoparticles at process of their restoration is developed.

It was established that depending on concentration of polymeric substrate, silver ions and UV-irradiation, spherical and rod-like stabilized silver nanoparticles of different sizes form in the structure of Na-CMC. The conditions of the formation of silver nanoparticles with different shape and size in dependence of components interaction reaction parameters and photochemical restoration were revealed.

Correlation dependence between the size and shape of silver nanoparticles in Na-CMC structure and their biological activity was established. It was shown that size of the silver nanoparticles decreasing promotes the increase of their antimicrobial activity at the same concentrations in polymeric matrix. The prepared biodegradable Na-CMC hydrogels contained silver nanoparticles are of interest as bactericidal and bacteriostatic covering agents for the treatment of burns and trophic ulcers.

\section{Acknowledgements}

This work was supported by the grants of Committee for Science and technology of Uzbekistan FA-A-13-T011 < <Development of technology for nanostructured biodegradable bactericidal materials for the treatment of wounds, burns and trophic ulcers $>>$ and YA-12-2 $<<$ Production technology of bactericidal, biodegradable films for medical purpose $>>$. The authors would like to thank to Rashidova Sayora Sharaphovna, the Honoured Worker of Science of Republic Uzbekistan, Doctor of Chemical science, professor, academician of Academy of Sciences of RUz for giving direction and advice, and to the Laboratory of Physical-chemical Analysis for assistance in physical-chemical investigations and measurement of samples.

\section{Conflicts of Interest}

The authors declare no conflicts of interest regarding the publication of this paper. 


\section{References}

[1] Sherbakov, A.B., et al. (2006) Silver Preparations: Yesterday, Today and Tomorrow. Pharmaceutical Journal, 5, 45-57.

[2] Antonov, S.F., Paramonov, B.A., Drobitsa, V.P., Ribalchenko, O.V. and Shlyakov, A.M. (2008) Biocompatible Structures Containing Silver Nanoclusters and Their Use for the Treatment of Burns and Ulcers: Safety Study of Bioactivity. International Nanotechnology Forum, Moscow, Vol. 1, 134-135.

[3] Semkina, O.A., Javakhyan, M.A., Liauchuk, T.A., et al. (2005) Excipients Used in the Art Dosage Forms (Ointments, Gels, Liniments, Creams). Chemical-Pharmaceutical Journal: Scientific and Technical Trade Journal, 39, 45-48.

[4] Rogovin, Z.A. (1972) Cellulose Chemistry. Publishing "Chemistry", Moscow.

[5] Sarymsakov, A.A. (2005) Medium- and Low-Substituted Carboxymethyl Cellulose-Preparation, Properties and Applications. Book, Tashkent.

[6] Pyatnitskiy, I.V. and Suchan, V.V. (1975) Analytical Chemistry of Silver. Nauka, Moscow. 264 p.

[7] Chen, D., Xi, T. and Bai, J. (2007) Biological Effects Induced by Nanosilver Particles: In Vivo Study. Biomedical Materials, 3, 126-128. https://doi.org/10.1088/1748-6041/2/3/S08

[8] Courrol, L.C. (2007) A Simple Method to Synthesize Silver Nanoparticles by Photo-Reduction. Lilia Coronato Courrol, Flravia Rodrigues de Oliveira Silva, Larercio Gomes. EPUSP, 18, 12-16.

[9] Loginov, A.V., Gorbunova, V.V. and Boysova, T.B. (1997) Methods for Preparation of Metal Colloids. Journal General Chemistry, 6, 189-200.

[10] Yunusov, K.E., Sarymsakov, A.A., Atakhanov, A.A., Ashurov N.S. and Rashidova S.S. (2011) Physicochemical Studies of Cotton Cellulose and Its Derivatives Containing Silver Nanoparticles. Chemistry of Natural Compounds, 47, 370-373. https://doi.org/10.1007/s10600-011-9947-8

[11] Mott, N.F. and Gurney, R.W. (1940) Electronic Processes in Ionic Crystals. Oxford University Press, New York City.

[12] Oksigenler, B.L., Turaeva, N.N., Yunusov, K.E., Sarymsakov, A.A. and Rashidova, S.S. (2009) The Mechanism of the Influence of Ultraviolet Radiation on the Growing and Properties of Silver Nanoparticles in the Polymer Solutions. Book of Abstracts, Tashkent, 82-85.

[13] Kreibig, U. and Vollmer, M. (1995) Optical Properties of Metal Clusters. Springer, Berlin. https://doi.org/10.1007/978-3-662-09109-8

[14] Sergeev, B.M., Kiryuhin, M.V., Prusov, A.N. and Sergeyev, V.G. (1999) Preparation of Silver Nanoparticles in Aqueous Solution of Polyacrylic Acid. Bulletin of Moscow State University, Series of Chemistry I, 40, 129-133.

[15] Mirzoeva, A.E. (2002) Methods for General Bacteriology. Moscow.

[16] Shahverdi, A.R., Fakhimi, A., Shahverdi, H.R. and Minaian, S. (2007) Synthesis and Effect of Silver Nanoparticles on the Antibacterial Activity of Different Antibiotics against Staphylococcus Aureus and Escherichia Coli. Nanomedicine, 3, 168-171. https://doi.org/10.1016/j.nano.2007.02.001

[17] Yunusov, K.E., Sarymsakov, A.A. and Rashidova, S.S. (2014) Structure and Properties of Biodegradable Carboxymethyl Cellulose Films Containing Silver Nanoparticles. Polymer Science: Series A, 56, 276-281. https://doi.org/10.1134/S0965545X14030183 